\title{
A 46-year-old man with acute low-back pain
}

\section{Andrea D. Furlan MD PhD, Laura Murphy PharmD}

\begin{abstract}
A 46-year-old man presents to his family physician with a week's history of intermittent lowback pain of moderate intensity (average intensity 6/10). On the body pain diagram, he marks only a small central area around L5. The pain is aggravated by bending forward (intensity $8 / 10$ ) and is completely alleviated when he lies down (intensity 0/10). The pain affects the patient's performance at work in a factory. $\mathrm{He}$ has hypertension, which is well controlled with ramipril and hydrochlorothiazide.
\end{abstract}

\section{Should radiology investigations be ordered for this patient?}

The likely diagnosis is intermittent mechanical back-dominant pain. As supported by Choosing Wisely Canada recommendations (Box 1), no imaging is needed unless there are red flags. These include major motor weakness, disturbance of bowel or bladder control, fever, immunosuppression, trauma, weight loss, morning stiffness greater than 1 hour, and pain worse at night or supine. ${ }^{1}$ Spinal "abnormalities" seen on imaging in asymptomatic individuals are common and increase with age, and most of the findings have no correlation with the clinical picture, especially in backdominant pain. ${ }^{2}$ In this patient's case, re-evaluation is needed if his symptoms do not improve substantially after about one month.

\section{Should the patient's physician endorse absence from work?}

There is no need to recommend bed rest or absence from work, a position supported by Choosing Wisely Canada (Box 1). A Cochrane review found that patients with acute low-back pain experienced small benefits in pain relief and functional improvement from advice to stay active compared with advice to rest in bed. ${ }^{3}$ There is expert consensus to support the positive link between work and physical, mental and social health. ${ }^{4}$ This patient may need modified work, such as more frequent break periods and avoidance of heavy lifting and bending forward.

\section{What nonpharmacologic therapy should be prescribed for this patient?}

There is evidence from systematic reviews to support the use of superficial heat (benefit over placebo, acetaminophen or ibuprofen), ${ }^{5}$ spinal manipulation (benefit over sham therapy), ${ }^{6}$ massage (benefit over inactive control) ${ }^{7}$ and acupuncture (benefit over no treatment) ${ }^{8}$ in patients with acute low-back pain. For flexion-aggravated low-back pain, home exercises are indicated and should include repeated passive extension in the lying position progressing to standing (see link to CORE Back Tool and other useful tools in Appendix 1, available at www.cmaj.ca/lookup/suppl/doi:10 .1503/cmaj.150660/-/DC1).

\section{Should non-opioid pharmacologic therapy be prescribed for this patient?}

Acetaminophen may be prescribed as a therapeutic trial, although recent evidence from randomized trials has shown that it is not effective for reducing pain, disability or recovery time in people with acute low-back pain. ${ }^{9}$ Nonsteroidal anti-inflammatory drugs (NSAIDs) may be prescribed as a therapeutic trial, given that the evidence has shown small improvement in pain intensity. ${ }^{10}$ However, Choosing Wisely Canada recommends against prescribing NSAIDs (including cyclo-oxygenase type 2 inhibitors) for patients with hypertension because of potential cardiovascular and renal complications (Box 1). Skeletal muscle relaxants (e.g., methocarbamol) reduce pain and improve function, ${ }^{10}$ but common adverse effects include sedation and drowsiness, which could impair this patient's performance and safety at work.

\section{Should opioids be prescribed for this patient?}

Opioids should not be prescribed for intermittent acute back-dominant pain, a position supported by Choosing Wisely Canada (Box 1). Observational studies showed a positive association with
Competing interests:

Andrea Furlan is creator of the Opioid Manager and co-creator of the My Opioid Manager apps. Both apps are owned by the University Health Network (UHN), and the project was funded by the Toronto

Rehabilitation

Institute-UHN and a New Investigator Award from the Canadian Institutes of Health Research. No other competing interests were declared.

This article has been peer reviewed.

The clinical scenario is fictional.

Correspondence to: Andrea Furlan, andrea.furlan@uhn.ca

CMAJ 2016. DOI:10.1503 /cmaj.150660 
opioid use for acute low-back pain and increased work disability in the long term. ${ }^{11}$ It is well known that opioids can result in euphoria, drowsiness or inability to concentrate, which can negatively affect work status, function and safety to drive a motor vehicle or operate machinery. Patients starting opioid treatment are at risk of continuing them long term, and prolonged use may lead to tolerance and the need for higher doses, opioid dependence or opioid use disorder. ${ }^{12}$

\section{The case revisited}

The patient stayed at work on modified duties (avoiding heavy lifting and bending forward). $\mathrm{He}$ performed exercises at work and at home (repeated passive extension in the lying position,

\section{Box 1: Choosing Wisely Canada recommendations*}

Don't do imaging for lower-back pain unless red flags are present (CSS, CAR, OMSC, CFPC)

- Red flags include, but are not limited to, severe or progressive neurological deficits or when serious underlying conditions such as osteomyelitis are suspected.

- Imaging of the lower spine before six weeks does not improve outcomes.

- Unnecessary imaging can be harmful because of the potential adverse health effects associated with radiation exposure and because of attribution of symptoms to unrelated incidental findings leading to prolonged disability.

- In patients with suspected uncomplicated herniated disc or spinal stenosis, imaging is indicated only after at least a six-week trial of conservative management and if symptoms are severe enough that surgery is being considered.

Don't endorse clinically unnecessary absence from work (OMSC)

- Absence from work contributes to declining health, slower recovery times and longer duration of disability.

- When asked to provide an opinion on functional abilities to employers or insurers, the focus should be on abilities; restrictions should be objective, specific, and listed only when absolutely medically indicated.

Don't prescribe nonsteroidal anti-inflammatory drugs (NSAIDs) for individuals with hypertension or heart failure or chronic kidney disease from all causes, including diabetes (CSN)

- The use of NSAIDs, including cyclo-oxygenase type 2 inhibitors, for the pharmacologic treatment of musculoskeletal pain can elevate blood pressure, make antihypertensive drugs less effective, cause fluid retention and worsen kidney function in these individuals.

Don't prescribe opiates for the treatment of acute or chronic noncancer pain without first assessing adverse effects, work status and capacity to drive a motor vehicle (OMSC)

- Compared with individuals prescribed lower or no opiate doses, those prescribed higher opiate doses have increased risk and duration of disability.

- Opioids can result in effects such as euphoria, drowsiness or inability to concentrate. Cognitive and psychomotor ability are essential functions for driving a motor vehicle and other complex work tasks.

*The list is a compilation of recommendations from national societies participating in the Choosing Wisely Canada program (www.choosingwiselycanada.org). The individual societies are indicated in parentheses. CAR = Canadian Association of Radiologists, CFPC = College of Family Physicians of Canada, CSN = Canadian Society of Nephrology, CSS = Canadian Spine Society, OMSC = Occupational Medicine Specialists of Canada. progressing to the standing position) and applied hot wraps daily. He used acetaminophen at a total daily dose of $3200 \mathrm{mg}$ for one week but reported no additional benefit, so the drug was stopped. A trial of naproxen at the lowest possible dose (250 mg orally twice daily) for two weeks helped him to stay at work and did not increase his blood pressure. He continued to have residual pain (intensity 3/10) for about four months, but he could manage with daily home exercises, heat and weekly massage sessions.

\section{References}

1. Physicians of Ontario Collaborating for Knowledge Exchange and Transfer. Red and yellow flag indicator cards. In: Physicians' Low-Back Pain Tool Kit. Toronto: Institute for Work and Health; 2005. Available: www.iwh.on.ca/physicians-network -tool-kit (accessed 2015 Dec. 14)

2. Chou R, Qaseem A, Owens DK, et al. Diagnostic imaging for low back pain: advice for high-value health care from the American College of Physicians. Ann Intern Med 2011;154:181-9.

3. Dahm KT, Brurberg KG, Jamtvedt G, et al. Advice to rest in bed versus advice to stay active for acute low-back pain and sciatica. Cochrane Database Syst Rev 2010;(6):CD007612.

4. Stay-at-Work and Return-to-Work Process Improvement Committee. Preventing needless work disability by helping people stay employed. J Occup Environ Med 2006;48:972-87.

5. French SD, Cameron M, Walker BF, et al. Superficial heat or cold for low back pain. Cochrane Database Syst Rev 2006;(1): CD004750.

6. Chou R, Huffman LH. Nonpharmacologic therapies for acute and chronic low back pain: a review of the evidence for an American Pain Society/American College of Physicians clinical practice guideline. Ann Intern Med 2007;147:492-504

7. Furlan AD, Giraldo M, Baskwill A, et al. Massage for low-back pain. Cochrane Database Syst Rev 2015;(9):CD001929.

8. Furlan AD, Yazdi F, Tsertsvadze A, et al. A systematic review and meta-analysis of efficacy, cost-effectiveness, and safety of selected complementary and alternative medicine for neck and low-back pain. Evid Based Complement Alternat Med 2012;2012:953139.

9. Machado GC, Maher CG, Ferreira PH, et al. Efficacy and safety of paracetamol for spinal pain and osteoarthritis: systematic review and meta-analysis of randomised placebo controlled trials. BMJ 2015;350:h1225.

10. Chou R. Pharmacological management of low back pain. Drugs 2010;70:387-402.

11. Furlan AD, Carnide N. Opioids for workers with an acute episode of low-back pain. Pain 2010;151:1-2.

12. Kaplovitch E, Gomes T, Camacho X, et al. Sex differences in dose escalation and overdose death during chronic opioid therapy: a population-based cohort study. PLOS ONE 2015;10:e0134550.

Affiliations: Toronto Rehabilitation Institute (Furlan, Murphy), University Health Network; Institute for Work and Health (Furlan); Department of Medicine (Furlan) and Leslie Dan Faculty of Pharmacy (Murphy), University of Toronto, Toronto, Ont.

Contributors: Both authors contributed substantially to the conception and design of the manuscript, drafted and revised it critically for important intellectual content, approved the final version to be published and agreed to act as guarantors of the work.

CMAJ is collaborating with Choosing Wisely Canada (www.choosingwiselycanada.org), with support from Health Canada, to publish a series of articles describing how to apply the Choosing Wisely Canada recommendations in clinical practice. 